\title{
Quorum-Quenching Bacteria Isolated From Red Sea Sediments Reduce Biofilm Formation by Pseudomonas aeruginosa
}

\author{
Zahid Ur Rehman* and TorOve Leiknes* \\ Water Desalination and Reuse Center, King Abdullah University of Science and Technology, Thuwal, Saudi Arabia
}

Quorum sensing (QS) is the process by which bacteria communicate with each other through small signaling molecules such as $N$-acylhomoserine lactones (AHLs). Certain bacteria can degrade $\mathrm{AHL}$ molecules by a process called quorum quenching (QQ); therefore, $Q Q$ can be used to control bacterial infections and biofilm formation. In this study, we aimed to identify new species of bacteria with $Q Q$ activity. Red Sea sediments

OPEN ACCESS

Edited by:

Gillberto Igrejas,

University of Trás-os-Montes

and Alto Douro, Portugal

Reviewed by:

Ariel Kushmaro,

Ben-Gurion University of the Negev,

Israel

Elizabeth Harvey,

Skidaway Institute of Oceanography,

United States

*Correspondence:

Zahid Ur Rehman

zahid.urrehman@kaust.edu.sa

TorOve Leiknes

torove.leiknes@kaust.edu.sa

Specialty section:

This article was submitted to Antimicrobials, Resistance and Chemotherapy,

a section of the journal

Frontiers in Microbiology

Received: 13 August 2017 Accepted: 05 June 2018

Published: 17 July 2018

Citation:

Rehman ZU and Leiknes T (2018) Quorum-Quenching Bacteria Isolated From Red Sea Sediments Reduce Biofilm Formation by Pseudomonas aeruginosa. Front. Microbiol. 9:1354. doi: 10.3389/fmicb.2018.01354 were collected either from the close vicinity of seagrass or from areas with no vegetation. We isolated 72 bacterial strains, which were tested for their ability to degrade/inactivate AHL molecules. Chromobacterium violaceum CV026-based bioassay was used for the initial screening of isolates with $Q Q$ activity. $Q Q$ activity was further quantified using high-performance liquid chromatography-tandem mass spectrometry. We found that these isolates could degrade AHL molecules of different acyl chain lengths as well as modifications. 16S-rRNA sequencing of positive $Q Q$ isolates showed that they belonged to three different genera. Specifically, two isolates belonged to the genus Erythrobacter; four, Labrenzia; and one, Bacterioplanes. The genome of one representative isolate from each genus was sequenced, and potential $Q Q$ enzymes, namely, lactonases and acylases, were identified. The ability of these isolates to degrade the 3OXOC12-AHLs produced by Pseudomonas aeruginosa PAO1 and hence inhibit biofilm formation was investigated. Our results showed that the isolate VG12 (genus Labrenzia) is better than other isolates at controlling biofilm formation by PAO1 and degradation of different AHL molecules. Time-course experiments to study AHL degradation showed that VG1 (genus Erythrobacter) could degrade AHLs faster than other isolates. Thus, QQ bacteria or enzymes can be used in combination with an antibacterial to overcome antibiotic resistance.

Keywords: quorum quenching, marine bacteria, $\mathbf{N}$-acylhomoserine lactone degradation, Red Sea sediments, biofilm inhibition

\section{INTRODUCTION}

Quorum sensing (QS) is the molecular mechanism by which bacteria monitor their population density in the local environment and regulate their behavior in a collective manner (Fuqua et al., 1994). QS is achieved by bacteria through the production of small chemical signaling molecules, collectively known as auto-inducers. Bacteria produce various kinds of auto-inducers that differ 
in chemical structure and mechanism of action. Broadly, autoinducers are categorized into three types: (i) acylhomoserine lactones (AHLs), (ii) auto-inducing peptides (AIPs), and (iii) auto-inducer 2 (AI-2) (Huang et al., 2016). QS is used by bacteria to regulate biofilm formation, conjugal DNA transfer, pathogenesis, production of extracellular polysaccharides, and other processes (Galloway et al., 2011). QS blockade is hypothesized to be of use to control infections and biofilm formation by bacteria.

Quorum quenching (QQ) refers to the mechanism by which bacterial communication can be interrupted. QQ can be achieved by inhibiting the production of auto-inducers, their detection by receptors, or their degradation (Natrah et al., 2011). Interference of QS by blocking signal production is not very common and few reports discuss this approach (Hentzer and Givskov, 2003). Many organisms such as algae (Givskov et al., 1996), plant (Gao et al., 2003), and bacteria (Teasdale et al., 2009) produce molecules that are structurally similar to AHLs, and therefore, competitively inhibit their binding to receptors. Certain mammalian cells (Yang et al., 2005) and bacteria (Dong and Zhang, 2005; Romero et al., 2011; Torres et al., 2016) produce enzymes that can degrade or modify AHLs. Bacteria from both terrestrial and marine environments are known to produce AHL-degrading/modifying enzymes (Dong et al., 2002; Romero et al., 2008). The widespread prevalence of QQ enzymes in bacterial communities suggest that it provides competitive advantage to the producer in terms of food and space.

In the wake of rising antimicrobial resistance and toxic impact of antimicrobials on the environment, it is necessary to explore alternative methods to control bacterial infections. QQ is one such alternative, which has been successfully tested in diverse industries (Bzdrenga et al., 2017). For example, QQ has been successfully employed to reduce the pathogenicity of common plant pathogens (Zhang et al., 2007). Similarly, QQ can reduce membrane biofouling in wastewater treatment plants (Oh et al., 2012; Kim et al., 2015; Huang et al., 2016). Successful utilization of QQ in lab-scale wastewater treatment plants has allowed its application in large pilot-scale wastewater treatment plants (Lee et al., 2016). In aquaculture industry, QQ has shown positive results in the disruption of bacterial infections (Cao et al., 2012; Romero et al., 2014; Vinoj et al., 2014; Torres et al., 2016). Recently, QQ was tested for its ability to mitigate the biofouling of reverse osmosis membranes used in seawater desalination (Oh et al., 2017). QQ also has other potential applications such as control of biofouling on the hulls of shipping vessels and fishnets and bio-corrosion of oil production wells. Therefore, there is a need to identify new/novel bacterial species that can produce robust enzymes for use in non-conventional environments; our study is an attempt toward this.

Bacteria can produce three different types of enzymes that can degrade or modify AHLs (Dong and Zhang, 2005): AHLlactonases hydrolyze the lactone moiety of AHLs (Dong et al., 2001), AHL-acylases hydrolyze the amide bond between lactone ring and acyl chain (Lin et al., 2003), and AHL-oxidoreductase oxidize or reduce the third carbon of the acyl chain of AHL molecules. Generally, hydrolysis of AHL molecules results in complete loss of activity, while oxidation/reduction reduces their activity (Chowdhary et al., 2007). This suggests that lactonases and acylases are more potent and useful in inhibiting bacterial communication.

Quorum quenching is gaining importance as a new way to control bacterial biofilms in medical and industrial domains, aquaculture, and water treatment plants (Torres et al., 2016; Bzdrenga et al., 2017). In this study, we attempted to isolate bacteria from sea sediments that can degrade AHLs and interfere with bacterial communication. We focused on QQ based on AHL inhibition because AHL-based QS is predominantly used by gram-negative bacteria, which are the dominant bacteria found in marine environments and are regarded as early colonizers during biofilm formation (Dang and Lovell, 2000; Zhang et al., 2006). For bacterial isolation, we used sediments from the Red Sea because this particular niche has not been explored from the point of view of QQ. Furthermore, this niche might help us identify new/novel species of bacteria that can be used for biofilm control for applications wherein terrestrial bacteria cannot be used. Screening of these isolates helped identify bacteria with QQ activity. Sequencing the genomes of these isolates allowed us to identify open reading frames (ORFs) encoding QQ enzymes. We further showed that these isolates can be used to degrade a wide range of AHL molecules as well as inhibit biofilm formation by Pseudomonas aeruginosa PAO1.

\section{MATERIALS AND METHODS}

\section{Sample Collection and Isolation of Bacteria}

Red Sea sediment cores were collected at a depth of 1-2 m from the coastal area (22.389778 and 39.135556) $12 \mathrm{~km}$ north of Thuwal, Saudi Arabia, in February 2016. Samples were collected from two different areas: one with vegetation (seagrass) and one without vegetation. Sediments were sampled using 30-cm-long acrylic cylindrical tube with a diameter of $5 \mathrm{~cm}$. An $\sim 20-\mathrm{cm}$ sediment core was collected, and the remaining headspace was filled with indigenous seawater. After sediment collection, rubber stoppers were inserted to seal the two ends of the cylinder. Sampled sediments were stored at $30^{\circ} \mathrm{C}$ and used to isolate QQ bacteria at the earliest to avoid any negative effect of storage. About $1 \mathrm{~g}$ of sea sediments collected from a depth of $2 \mathrm{~cm}$ from the surface of the sampling cylinder was suspended in $1 \mathrm{~mL}$ of $0.2-\mu \mathrm{m}$ filtered autoclaved seawater and vortexed. Samples were allowed to stand for 1-2 min to allow the particles to settle down. The supernatant was then subjected to 10-fold serial dilution. Each dilution was plated on Marine Agar (MA) (HIMEDIA, India), R2A agar (HIMEDIA, India), and Casamino acids (CAS) agar (VWR, United States). Both R2A and CAS agar were prepared in $75 \%$ of $0.2-\mu \mathrm{m}$-membrane-filtered autoclaved seawater. The plates were incubated at $30^{\circ} \mathrm{C}$ for 1 week. Colony-forming units observed on plates (with 30-300 colonies) were enumerated, and the colonies were further subcultured onto sterile agar plates based on macroscopic characteristics. Single colonies were further streaked twice to obtain pure cultures. 


\section{QQ Assay}

The isolated strains were tested for QQ activity by using the AHL biosensor strain Chromobacterium violaceum CV026. This sensor strain has been used to detect C6-AHLs in various studies (McClean et al., 1997; Romero et al., 2011; Torres et al., 2016). The isolates were grown in $0.5 \mathrm{~mL}$ of the isolation medium and incubated at $30^{\circ} \mathrm{C}$ with shaking at $150 \mathrm{rpm}$. C6-AHLs were added to this bacterial culture to reach a final concentration of $10 \mu \mathrm{M}(2 \mu \mathrm{g} / \mathrm{mL})$ and further incubated for $24 \mathrm{~h}$ at $30^{\circ} \mathrm{C}$ with shaking. The $\mathrm{pH}$ of this mixture was measured to confirm that the observed degradation of AHLs was not caused by alkaline pH (Yates et al., 2002). C6-AHLs mixed with cell-free medium were used as the negative control. The bacterial cultures were centrifuged to pellet the cells, and the remaining C6-AHLs in the culture supernatant were detected by the following method. Luria-Bertani (LB) agar plates were overlaid with $5 \mathrm{~mL}$ of $1 / 100$ th-dilution of an overnight culture of the biosensor strain CV026 mixed with LB soft agar (0.7\%). After the biosensor layer was solidified, $6-\mathrm{mm}$ wells were created in the medium by using sterile pipette tips. These wells were filled with the culture supernatant and incubated at $30^{\circ} \mathrm{C}$ for $24 \mathrm{~h}$. Solvent without C6-AHLs was used as the blank. The appearance of a purple halo around the well-indicated the absence of QQ activity. On the other hand, strains with QQ activity degraded C6-AHLs, and therefore, the biosensor strain was not activated. Thus, halo formation was not observed. Furthermore, the culture supernatant of QQ isolates was tested for the production of C6-AHLs.

No purple halos were observed in the CAS and R2A cellfree media (negative controls), which showed that these media cannot be used for QQ assay. Therefore, for these isolates, we slightly modified the QQ assay, as described previously (Uroz et al., 2005; Shepherd and Lindow, 2009). Briefly, 24-h-old bacterial cultures were centrifuged to obtain cell pellets. These pellets were suspended in $0.5 \mathrm{~mL}$ of $1 \mathrm{X}$ phosphate-buffered saline (PBS) containing $10 \mu \mathrm{M}$ C6-AHLs and incubated overnight at $30^{\circ} \mathrm{C}$ with shaking. The remaining procedure was as described above.

\section{QQ Assay With Heat-Inactivated Bacteria}

To ensure that the loss of C6-AHL activity observed in QQpositive strains was not due to the adsorption of these molecules onto the cell surface, the bacterial cells were heat killed. Bacterial cells were heated at $100^{\circ} \mathrm{C}$ for $15 \mathrm{~min}$. Heat-killed bacterial cells were allowed to cool down for $10 \mathrm{~min}$ at room temperature. QQ assay was performed as described above. Bacterial cell death was confirmed by plating $150 \mu \mathrm{L}$ of the heat-treated cell suspension on respective culture medium.

\section{Detection and Localization of AHL-Degradation Activity}

This assay was performed as described previously with slight modifications (Romero et al., 2008; Torres et al., 2016). About $200 \mathrm{~mL}$ of the overnight culture suspension of QQ-positive isolates was centrifuged at $7000 \times g$ for $10 \mathrm{~min}$. Cell pellets were washed with an equal volume of $1 \mathrm{X}$ PBS and re-suspended in
$50 \mathrm{~mL}$ of PBS. Cells were lysed by intermittent ultra-sonication (Qsonica, United States) for $5 \mathrm{~min}$ in a cold water bath at a frequency of $15 \mathrm{kHz}$. Lysed cells were centrifuged at $16000 \times g$ for $30 \mathrm{~min}$ at $4^{\circ} \mathrm{C}$. Cell lysates were filtered through a $0.2-\mu \mathrm{m}$ pore-sized-membrane filter. The protein concentration of the cell lysates was determined with Qubit (Invitrogen, United States). To determine AHL-degradation activity, $500 \mu \mathrm{L}$ of the cell lysates was incubated with $10 \mu \mathrm{M}$ C6-AHLs for $24 \mathrm{~h}$ at $30^{\circ} \mathrm{C}$, with shaking at $140 \mathrm{rpm}$. The remaining C6-AHLs were detected by a well-diffusion agar plate assay, as described above. Cell lysate without C6-AHLs was used as the control. To understand the chemical nature of QQ activity, the cell lysates were heated at 95 and $105^{\circ} \mathrm{C}$ for $10 \mathrm{~min}$. Furthermore, the cell lysates were fractionated using $10-\mathrm{kDa}$ centrifugal filters (Amicon, United States) and QQ activity was analyzed for both the retentate and filtrate of cell lysates.

\section{HPLC-MS-Based Analysis of AHLs}

The ability of isolates to degrade different types of AHLs was studied by using high-performance liquid chromatographytandem mass spectrometry (HPLC-MS) as described previously (Romero et al., 2011). Briefly, overnight bacterial cultures were centrifuged and re-suspended in PBS containing $10 \mu \mathrm{M}$ AHL. This mixture was incubated overnight at $30^{\circ} \mathrm{C}$ with shaking. For the time-course experiment, the samples were withdrawn every hour for $5 \mathrm{~h}$. To extract AHLs, the cells were separated by centrifugation at $7000 \times g$ for $5 \mathrm{~min}$, and the PBS was extracted twice with an equal volume of ethyl acetate (Fisher Scientific, United States). Ethyl acetate was evaporated under a flux of nitrogen at $40^{\circ} \mathrm{C}$, and the final extract was suspended in $400 \mu \mathrm{L}$ of acetonitrile (Fisher Scientific, United States) for HPLC-MS. PBS containing equal amount of AHLs was used as the negative control. To determine whether the QQ activity was caused by the hydrolysis of lactone ring (lactonolysis), the bacterial cells were incubated overnight with PBS containing $50 \mu \mathrm{M} 3 \mathrm{OHC10}$-AHLs. The cellfree supernatant was acidified to a $\mathrm{pH}$ of 2 by adding $10 \mathrm{mM}$ hydrochloric acid $(\mathrm{HCl})$. The acidified supernatant was incubated overnight at room temperature to allow re-cyclization of lactone ring. AHLs were extracted from this solution as described above.

High-performance liquid chromatography 1100 series equipped with ZORBAX Eclipse XDB-C18 (4.6 mm $\times 250 \mathrm{~mm}$ column; 5- $\mu \mathrm{m}$ particle size; Agilent Technologies, United States) kept at $45^{\circ} \mathrm{C}$ was used for analysis. About $10 \mu \mathrm{L}$ of the extract was injected at a flow rate of $0.45 \mathrm{~mL} / \mathrm{min}$. For elution, a mobile phase consisting of solvent B (methanol with $0.1 \%$ formic acid) and solvent A (25 mM ammonium formate with $0.1 \%$ formic acid) was used. The gradient profile used was 1 min of $10 \%$ solvent B, followed by a linear gradient gradually increasing to $95 \%$ of solvent B over $15 \mathrm{~min}$. Solvent B (95\%) was then stabilized for $4 \mathrm{~min}$. The column was re-equilibrated for a total of $5 \mathrm{~min}$. MS data were obtained on TSQ Vantage triple-quadruple mass spectrometer (Thermo Fisher Scientific, United States) by using positive-ion electrospray and multiple-reaction-monitoring (MRM) mode. 


\section{Bacterial Identification Based on 16S-rRNA Gene Sequencing}

About $500 \mu \mathrm{L}$ of the overnight bacterial suspension was centrifuged and the cell pellets were re-suspended in $500 \mu \mathrm{L}$ of nuclease-free water. Bacterial cells were lysed by heating at $95^{\circ} \mathrm{C}$ for $10 \mathrm{~min}$, followed by cooling for $15 \mathrm{~min}$ at room temperature. The lysed bacterial cells were centrifuged at $12000 \times g$ for $3 \mathrm{~min}$, and $1 \mu \mathrm{L}$ of the supernatant was used as template DNA for polymerase chain reaction (PCR). A set of three primer pairs, namely, (27F-785R), (341F-907R), and (785F-1492R) was used to amplify the I6S-rRNA gene. Primer sequences are available in Supplementary Table 4. Following PCR conditions were used: initial denaturation at $95^{\circ} \mathrm{C}$, followed by 30 cycles of denaturation at $94^{\circ} \mathrm{C}$ for $30 \mathrm{~s}$; primer annealing at $52^{\circ} \mathrm{C}$ (27F-785R), $62^{\circ} \mathrm{C}$ (341F-907R), and $53^{\circ} \mathrm{C}$ (785F-1492R) for $30 \mathrm{~s}$; and extension at $72^{\circ} \mathrm{C}$ for $1 \mathrm{~min}$. Final extension was performed at $72^{\circ} \mathrm{C}$ for $5 \mathrm{~min}$. The PCR product was analyzed by gel electrophoresis and purified using the ExoSap-IT PCR product cleanup kit (Affymetrix, United States), according to manufacturer's instructions. The purified DNA was submitted for Sanger sequencing. The three overlapping sequences were aligned to obtain a single rRNA molecule for use in BLAST search (Altschul et al., 1997) against the 16S-rRNA gene sequences available in the GenBank database. The 16S-rRNA gene sequences of close relatives, as determined by BLAST and the QQ bacteria described in literature, were used for phylogenetic analysis.

For phylogenetic analysis, the SINA software package available in SILVA rRNA database (Quast et al., 2013) was used to align 16S-rRNA gene sequences. The aligned sequences were subjected to phylogenetic tree construction by using MEGA7 (Kumar et al., 2016) software at default parameters.

\section{Acylhomoserine Lactones (AHLs)}

Following AHLs were used in this study; N-butyryl-DLhomoserine lactone (C4-AHLs), $N$-hexanoyl-DL-homoserine lactone (C6-AHLs), $\mathrm{N}$-decanoyl-DL-homoserine lactone (C10AHLs), $N$-tetradecanoyl-DL-homoserine lactone (C14-AHLs), $\mathrm{N}$-(3-oxodecanoyl)- DL-homoserine lactone (3OXOC10-AHLs), $\mathrm{N}$-(3-hydroxydecanoyl)- DL-homoserine lactone (3OHC10AHLs), and $\mathrm{N}$-(3-oxododecanoyl)- L-homoserine lactone (3OXOC12-AHLs). All AHLs used in this study were purchased from Sigma, United States.

\section{Biofilm Formation and Quantification}

The impact of $\mathrm{QQ}$ bacteria on biofilm formation by $P$. aeruginosa PAO1 was studied using a recently described segregated culture bioassay (Oh et al., 2017). In this assay, QQ bacteria are physically separated from PAO1 by using a semipermeable membrane (Transwell polycarbonate membrane cell inserts; Corning, NY, United States). PAO1 $\left(\mathrm{OD}_{600}=0.01\right)$ was directly inoculated into the wells of a 24- or 6-well microtiter plates. QQ bacteria (live or dead) were added into the membrane inserts and installed into the wells. As a control, QQ bacteria were killed by incubating the cells in $4 \%$ paraformaldehyde for $30 \mathrm{~min}$ at room temperature. Cell death was confirmed by spreading the cell suspension on R2A or MA plates. The inoculated microtiter plates were incubated for $24 \mathrm{~h}$ at $30^{\circ} \mathrm{C}$ with shaking at $60 \mathrm{rpm}$. The membrane inserts were removed, and the $\mathrm{OD}_{600}$ of the PAO1 cell suspension was measured to determine the effects of QQ bacteria on growth, if any. Biofilm formation by PAO1 on the wells was measured using the crystal violet assay (Coffey and Anderson, 2014). PAO1 culture was also used for the extraction and quantification of 3OXOC12-AHLs, as described above. Furthermore, 3OXOC12-AHLs were quantified in the control sample (LB) as well as VG1, VG12, and NV9.

\section{Genome Sequencing and Annotation}

Genomic DNA of the strains to be sequenced was extracted using QIAGEN genomic-tip 100/G columns (QIAGEN, Germany). A genome-sequencing library was prepared using the Pacific Biosciences (PacBio) 20-kb template preparation kit by employing the BluePippin size selection system and sequenced on PacBio RS platform. The PacBio reads were assembled using the CANU WGS assembler version 1.4 (Koren et al., 2017). The assembled genome was annotated using the Automatic Annotation of Microbial Genomes (AAMG) pipeline (Alam et al., 2013). For functional annotation, the predicted ORFs were compared to the latest version of UniProt (The Uniprot Consortium, 2017) and Kyoto Encyclopedia of Genes and Genomes (KEGG) (Kanehisa et al., 2014).

\section{Statistical Analysis}

Mean and standard deviation were calculated for AHL degradation and biofilm inhibition assays. Further statistical analyses such as analysis of variance (ANOVA) with Bonferroni corrected post hoc $t$-test and also Student's $t$-test were preformed where statistical significance was ( $p$-value $<0.0063)$ or $(p$-value $<0.05)$ respectively. All the statistical analyses were performed in Microsoft ${ }^{\circledR}$ Excel version 16.9.

\section{RESULTS}

\section{Bacterial Isolates}

Different number of CFUs were obtained, from both types of sea sediment samples by using three different culture media. The CFU/gram of sea sediment is listed in Supplementary Figure 1. For all culture media, the number of CFUs obtained from the samples from non-vegetative areas was higher compared to that from the samples collected from the vicinity of vegetation (Supplementary Figure 1).

Higher CFUs were observed on MA medium, compared to R2A and CAS media. The highest number of CFUs, that is, $6.6 \times 10^{4}$, was obtained from the samples obtained from non-vegetative areas that were plated on MA. For the samples collected from the vicinity of vegetation, $4.4 \times 10^{4}$ CFUs were obtained on MA (Supplementary Figure 1), which was fourtimes higher than that obtained on R2A and CAS media. Isolates exhibiting different colony morphology were selected for QQ assay. 


\section{Biosensor-Based Detection of $\mathbf{Q Q}$ Activity}

About 71 bacterial isolates were screened for QQ activity. A solid plate assay was performed using the biosensor strain C. violaceum CV026, which produces a purple pigment violacein in response to C6-AHLs (McClean et al., 1997). The QQ strains can degrade AHLs, which, in turn, did not allow the development of any color. The number of isolates tested and those testing positive for QQ activity is listed in Table 1. Of the 14 QQ-positive isolates, 64.3\% were isolated on the R2A medium, followed by MA $(21.5 \%)$ and CAS (14.3\%). However, the QQ-positive CAS and MA isolates showed only partial degradation of C6-AHLs, as indicated by the small/faint purple halos (Supplementary Figures 2, 3). Most QQpositive isolates obtained on R2A showed complete degradation of AHLs. Overall, $22.4 \%$ isolates from the samples obtained from areas near vegetation and $13.6 \%$ isolates from the samples obtained from areas without vegetation were positive for QQ activity (Table 1). C6-AHL production by the QQ isolates was not detected.

Some previous studies investigating the QQ potential of marine bacteria used marine broth for QQ assay (Romero et al., 2011; Torres et al., 2016). Therefore, we tried to cultivate the isolates obtained on R2A and CAS media in marine broth. However, except VG12, none of them grew in marine broth, although they did grow on MA. VG12 cultivated in marine broth continued to remain positive for QQ activity.

Quorum quenching assay performed using heat-killed QQ isolates ruled out the possibility that the observed loss of AHLs was due to adsorption onto bacterial cells (data not shown). Bacterial isolates that retained QQ activity after heat treatment were not included in further analyses. Of the 14 isolates, eight were selected for further analyses.

\section{QQ Analysis Based on HPLC-MS}

The QQ activity of the positive strains, as determined by the biosensor assay, was further confirmed by HPLC-MS. The ability of QQ bacteria to degrade different types of AHLs was also investigated. For this, QQ-positive bacterial cultures were mixed with AHLs of different acyl chain lengths and modifications

TABLE 1 | Number and QQ activity of the strains isolated from different samples (vegetative and non-vegetative) by using different media.

\begin{tabular}{lcc}
\hline Sample/medium & Isolates tested for QQ & QQ based on CV026 \\
\hline Vegetative & 21 & 2 \\
MA & 18 & 7 \\
R2A & 10 & 2 \\
CAS & & \\
Non-vegetative & 6 & 1 \\
MA & 10 & 2 \\
R2A & 6 & 0 \\
CAS & 71 & 14 \\
Total &
\end{tabular}

Number of isolates with positive $Q Q$ activity (based on C6-AHL degradation in the Chromobacterium violaceum CV026 assay) is shown.
(C4-AHLs, C6-AHLs, C10-AHLs, 3OXOC10-AHLs, 3OHC10AHLs, and C14-AHLs). After $24 \mathrm{~h}$ of incubation, the final $\mathrm{pH}$ was $<7.5$, which excluded the possibility of the hydrolysis of the lactone ring of AHL molecules due to alkalinity. The remaining AHLs were extracted and quantified (Figures 1A-E, 2A). All the strains showed significant reduction in the amount of AHLs, compared to the negative control (Figure 1). Analysis of variance (ANOVA) along with Bonferroni's corrected post hoc t-test was applied, which showed significant reduction of AHLs by the QQ strains ( $p$-value $<0.0063$ ), compared to the blank sample. The degradation capacity of all isolates was higher for C10AHLs and C14-AHLs, compared to C6-AHLs (Figures 1A-C). All QQ bacteria caused $>90 \%$ reduction in the quantities of $\mathrm{C} 10$ and C14-AHLs (Figures 1A,B). These results are in agreement with previous reports wherein the reduction in the amount of long-acyl-chain AHLs was higher compared to that in case of short-acyl-chain AHLs (Romero et al., 2008; Romero et al., 2011; Torres et al., 2016).

The ability of these QQ bacteria to degrade differently modified C10-AHLs (3OXO-AHLs and 3OH-AHLs) was also investigated (Figures 1D,E). The strain VG16 displayed inconsistent cultivability; therefore, it was not included in further analyses. In a recent study, most QQ bacteria were able to degrade a wide range of AHLs, but they could not effectively degrade 3OHC10-AHLs (Torres et al., 2016). Similar to this, all QQ-positive isolates in this study could degrade 3OXOC10-AHLs more effectively, compared to 3OHC10-AHLs (Figures 1D,E).

We also studied the ability of bacteria to degrade C4-AHLs. For this analysis, three QQ-positive bacteria (VG1, VG12, and NV9) belonging to different genera were selected. Of these, VG12 showed maximum degradation (>80 $\pm 8.9 \%$ ) of C4-AHLs (Figure 2A), while NV9 showed only $26 \pm 13 \%$ reduction and VG1 did not show significant degradation (Figure 2A).

To identify the nature of QQ activity, i.e., lactonase or acylase, 3OXOC10-AHLs degraded by VG1, VG12, and NV9 were treated with $\mathrm{HCl}$. Acidification resulted in the reformation of lactone ring that suggested lactonase activity (Yates et al., 2002; Romero et al., 2008). In NV9, $~ 63.5 \pm 4 \%$ of 3OXOC10-AHLs was recovered after $\mathrm{HCl}$ treatment. In VG12 and VG1, only $2 \pm 0.003$ and $0.004 \pm 0.009 \%$ of AHLs, respectively, were recovered after acidification (Figure 2B).

\section{QQ Activity and Its Localization}

The location of QQ activity (extracellular or intracellular) was studied for VG1, VG12, and NV9. Cell-free supernatants and lysates were incubated with C6-AHLs. Cell lysates and culture supernatant of VG1 were able to degrade C6-AHLs (Supplementary Figure 2B). No QQ activity was detected in the culture supernatant and cell lysates of VG12 and NV9 (Supplementary Figure 2B). Heat treatment of the cell lysates of VG1 at 95 and $105^{\circ} \mathrm{C}$ did not result in loss of QQ activity. After fractionation of the cell lysates of VG1 by using $10-\mathrm{kDa}$ filters, QQ activity was detected only in the retentate but not in the filtrate (data not shown). This suggested that the molecules responsible for QQ activity are larger than $10-\mathrm{kDa}$. 
A

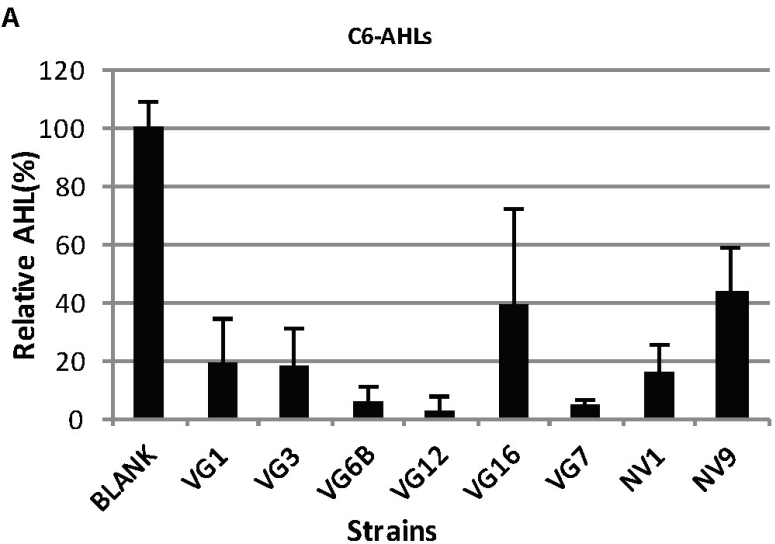

C

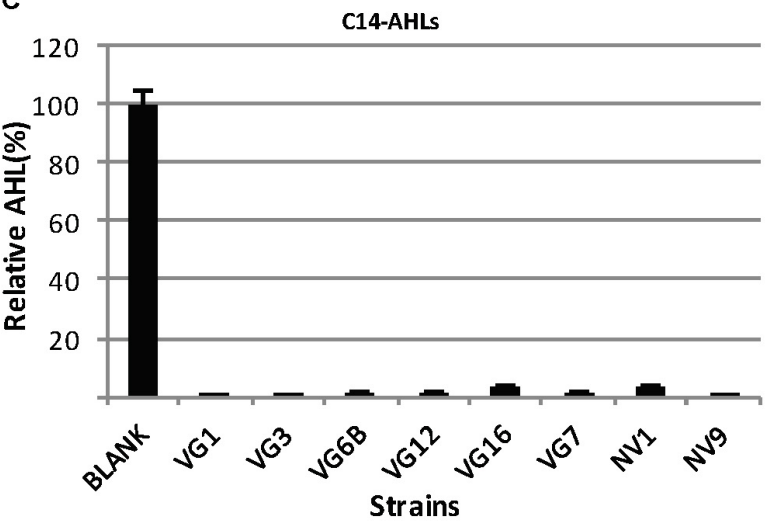

E

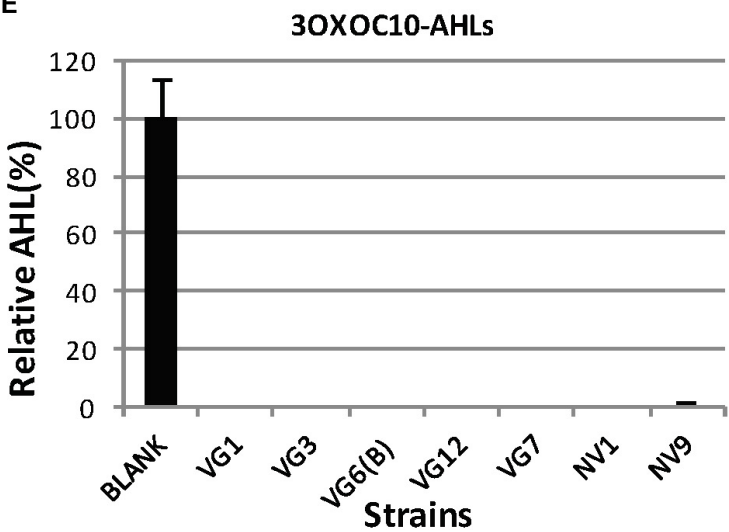

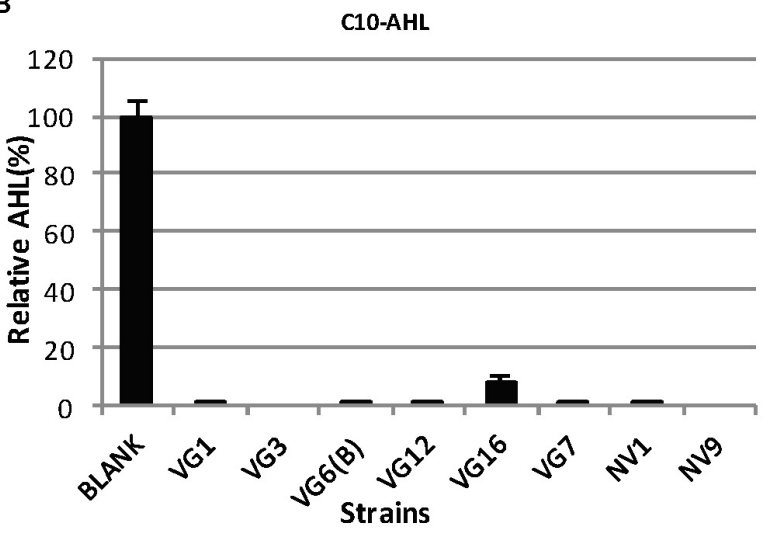

D

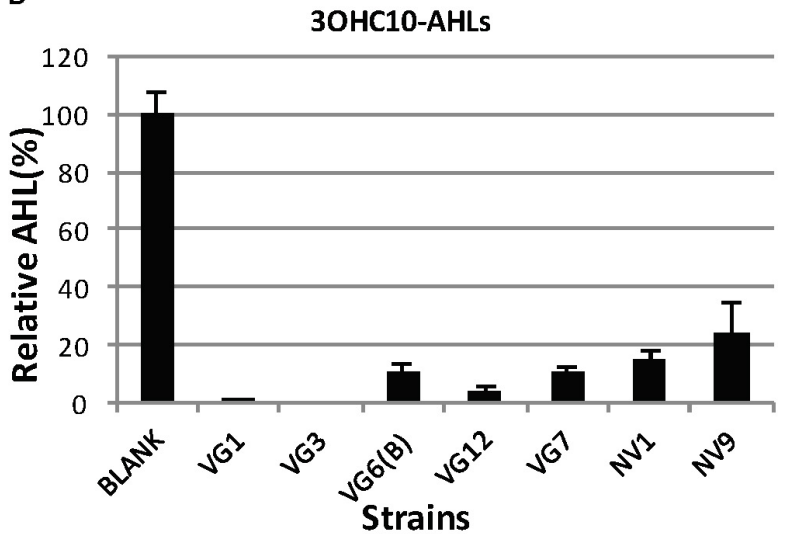

FIGURE 1 | Degradation of AHLs by the isolated bacteria. The amount of AHLs degraded by different isolates is listed, relative to the negative control. Quantification of AHLs was performed as described in Section "Materials and Methods." Briefly, AHLs were extracted with ethyl acetate, which was evaporated under a flux of nitrogen gas. The extracted AHLs were re-suspended in acetonitrile and quantified by HPLC-MS. Cell-free PBS was used as the negative control (100\%). Values are the mean of three replicates; error bars represent standard deviation. Charts (A-E) illustrates the degradation of C6, C10, C14, 3OXOC10-AHLs, and 3OHC10-AHLs, respectively.

\section{Time-Course Experiment of AHL Degradation}

The kinetics of the degradation of 3OXOC10-AHLs by VG1, VG12, and NV9 was also investigated. The isolate VG1 caused $98.7 \pm 0.11 \%$ reduction in the first hour, while VG12 caused $58 \pm 1.4 \%$ reduction and NV9 caused only $26.9 \pm 8.2 \%$ reduction in the amount of AHLs (Figure 3). However, after $2 \mathrm{~h}$, the amount of AHLs degraded by VG1 and VG12 was almost equal, i.e., $99.9 \pm 0.01$ and $98 \pm 0.7 \%$, respectively, while only $50 \pm 3.4 \%$ of the AHLs was degraded by NV9. Maximum reduction of 3OXOC10-AHLs by NV9 occurred after $4 \mathrm{~h}$ (Figure 3). 
A

C4-AHLS

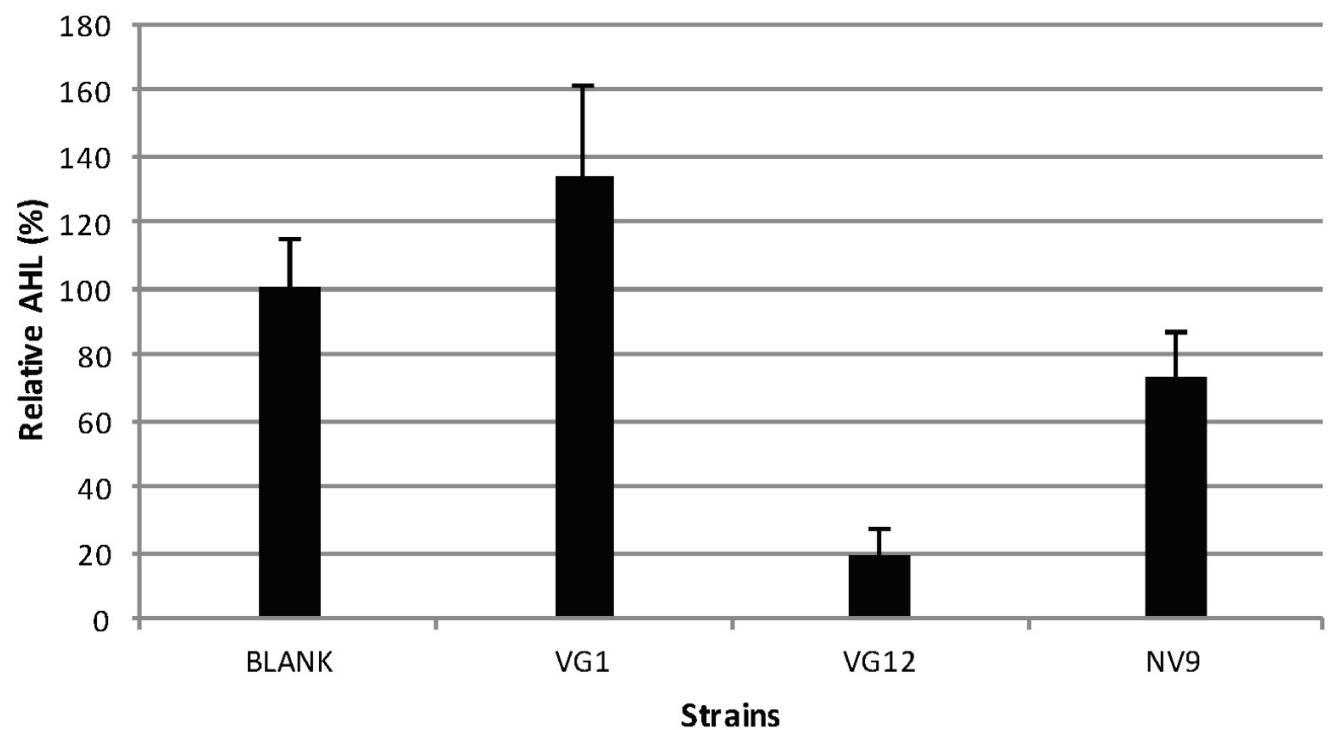

B

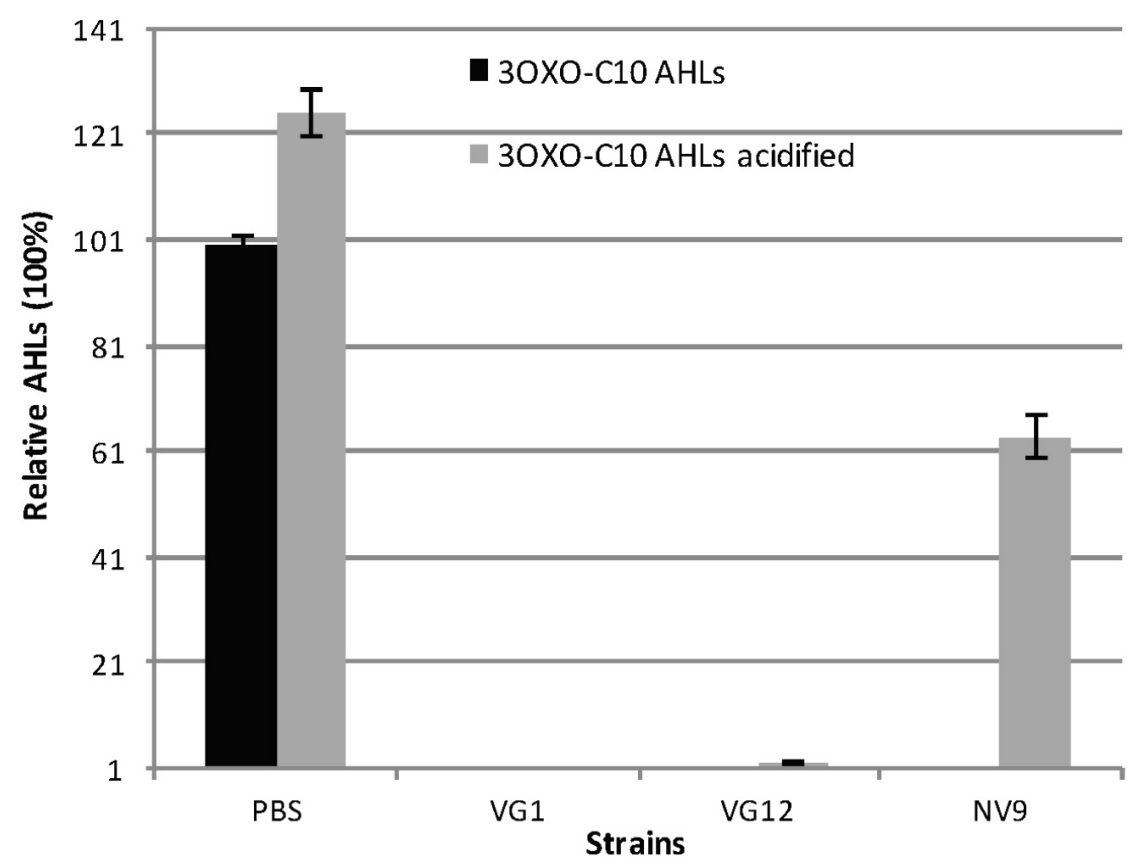

FIGURE 2 | Degradation and acidification of AHLs. (A) Relative amount of C4-AHLs degraded by the three isolates is given. For quantification, the C4-AHLs were extracted with ethyl acetate and subsequently dried and re-suspended in acetonitrile for injection in HPLC-MS. Cell-free PBS served as the negative control (100\%). Experiments were performed in triplicate; error bars represent the standard deviation of the mean value. Student's $t$-test showed significant reduction in the amount of C4-AHLs by VG12 ( $p$-value $=0.003$ ) and NV9 $(p$-value $=0.03)$. No significant degradation of C4-AHLs by VG1 was observed $(p$-value $=0.11)$. $(\mathbf{B})$ Acidification of 3OXOC10-AHLs after incubation with QQ bacteria. Relative amount of AHLs before and after acidification is given. Black bars represent the amount of AHLs after incubation with PBS (negative control is 100\%) or QQ bacteria. Gray bars represent the amount of AHLs recovered after acidification. Error bars represent the standard deviation for the three independent replicates.

\section{Identification of QQ Isolates}

Phylogenetic analyses showed that all the seven QQ isolates belonged to the phylum Proteobacteria (Supplementary Table 1).
Except NV9, all other isolates [VG1, VG3, VG6(B), VG12, VG7, and NV1] belonged to the class Alphaproteobacteria and two different genera Erythrobacter and Labrenzia. 


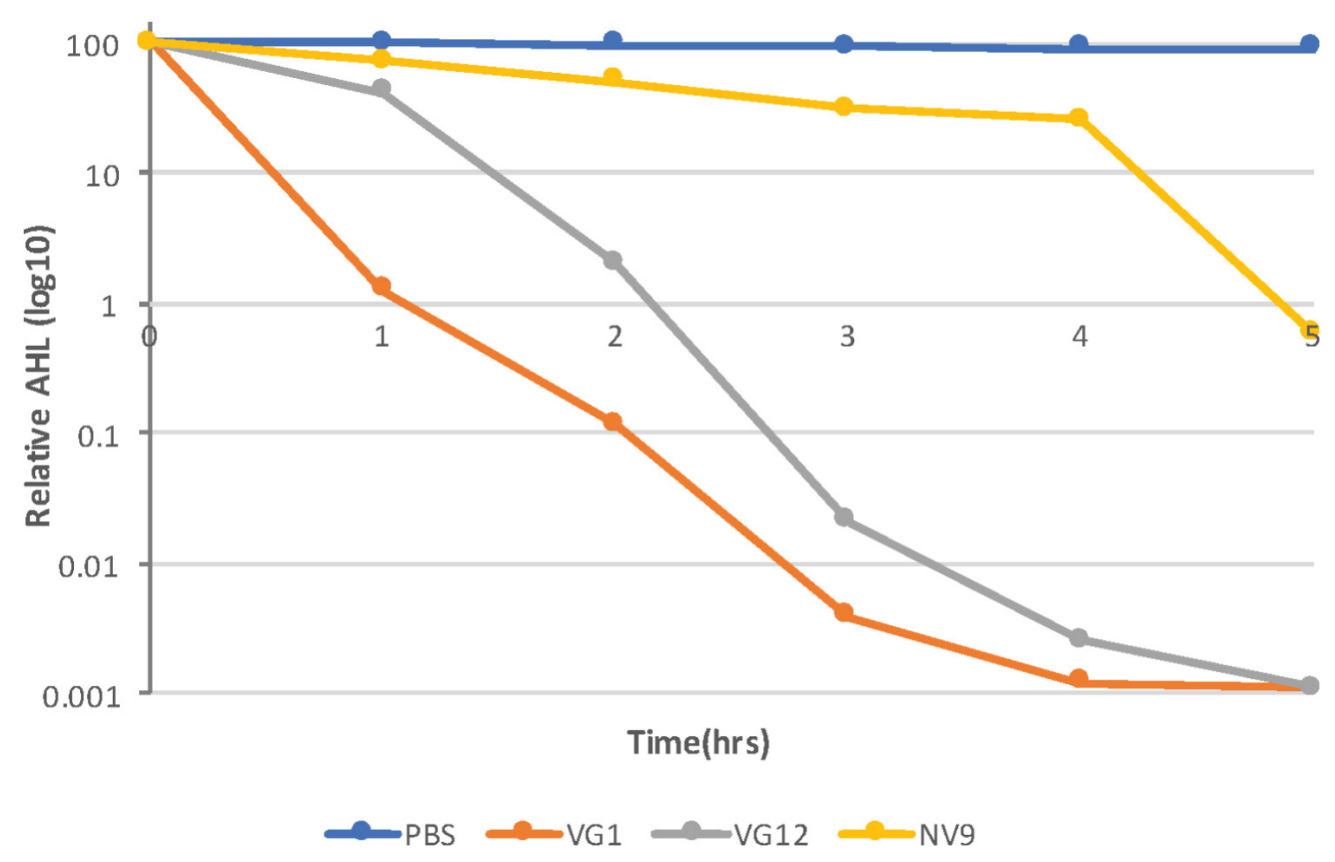

FIGURE 3 | Time-course experiment to study AHL degradation. Log 10 of the relative amount of AHLs quantified at each time point is given along the $y$-axis. AHLs were quantified using HPLC-MS, as described in Section "Materials and Methods." The amount of AHLs at $0 \mathrm{~h}$ is considered 100\%. Control (PBS) sample and different strains are represented by different colors, as indicated in the legend. Standard deviation at each time point was $<10 \%$.

Isolate NV9 belonged to the class Gammaproteobacteria and genus Bacterioplanes (Supplementary Figure 4 and Table 1).

Isolates VG1 displayed 100\% identity to Erythrobacter flavus SW-52, which was also isolated from the marine environment (Yoon et al., 2003). As described for E. flavus, VG1 formed yellow colonies on agar plates. Isolate VG3 showed 99\% identity to Erythrobacter sp. JL-378 and also formed yellow colonies on R2A agar.

Four isolates, namely, VG6(B), VG12, VG7, and NV1, belonged to the genus Labrenzia. Different species of Labrenzia that were identified based on 16S-rRNA gene sequence homology are listed in Supplementary Table 1. VG12 showed 99\% identity to Alphaproteobacterium JL001 that was isolated from marine sponges. Phylogenetic analysis showed that VG12 is closely related to the other Labrenzia species identified in this study and previously (Supplementary Figure 4). Isolate VG7 showed 99\% identity to Labrenzia sp. A-3-20, which was recently isolated from the soft corals found in Baltic sea (Pham et al., 2016). NV1 displayed 99\% identity to Labrenzia sp. R-666638. All species of genus Labrenzia that have been identified so far, have been isolated from marine environments (Biebl et al., 2007; Camacho et al., 2016).

The 16S-rRNA sequence of the QQ isolate NV9 (obtained from areas without vegetation) showed $99 \%$ identity to that of a recently proposed bacterial species Bacterioplanes sanyensis (Wang et al., 2014), also isolated from marine environment.

The phylogenetic relationship of the QQ isolates discussed in this study and other marine bacteria is illustrated in Supplementary Figure 4.

\section{Effect of QQ Bacteria on Biofilm Formation}

VG12 was able to significantly reduce biofilm formation by PAO1. Live VG12 cells could reduce biofilm formation by $25 \pm 0.018 \%$ compared to dead VG12 cells (Figure 4A). However, no significant reduction was induced by VG1 and NV9 in the biofilm formation of PAO1.

Pseudomonas aeruginosa PAO1 produces 3OXO-C12AHLs, which directly or directly control the expression of virulence factors and biofilm formation (Williams and Camara, 2009). Therefore, the amount of 3OXO-C12AHLs in the supernatant of PAO1 incubated with live/dead QQ bacteria was also quantified. However, no significant degradation of 3OXO-C12AHLs was detected (Figure 4B). No 3OXO-C12AHLs were detected in case of LB, VG1, VG12, and NV9.

\section{Identification of Lactonases and Acylases in the Genome Sequences}

For each strain, the genomic features and their counts are listed in Supplementary Table 3. The genome sequences were submitted to GenBank; the accession numbers for VG1 is CP022528, VG12 is CP022529, and NV9 is CP022530. Annotations for VG1 are available ${ }^{1}, \mathrm{VG}_{1}{ }^{2}$, and $\mathrm{NV}^{3}$. Based on average nucleotide identity (ANI), a new quality control test implemented by GenBank, VG12 was designated as Labrenzia sp. VG12

\footnotetext{
${ }^{1}$ https://bit.ly/2uoXhX1

${ }^{2}$ https://bit.ly/2mr70HU

${ }^{3}$ https://bit.ly/2NpfrPA
} 
A

口QQ(Live) $\mathbf{Q Q Q}($ Killed)

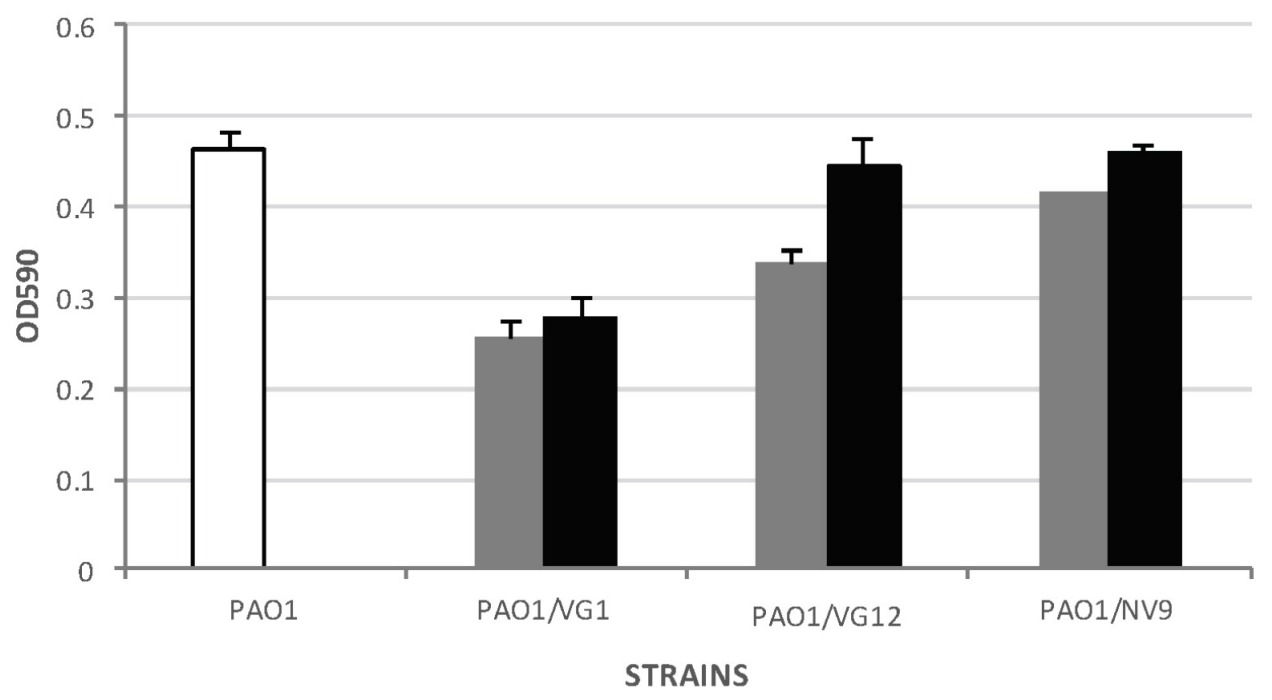

B

口QQ (Live) $\mathbf{Q Q}$ (Killed)

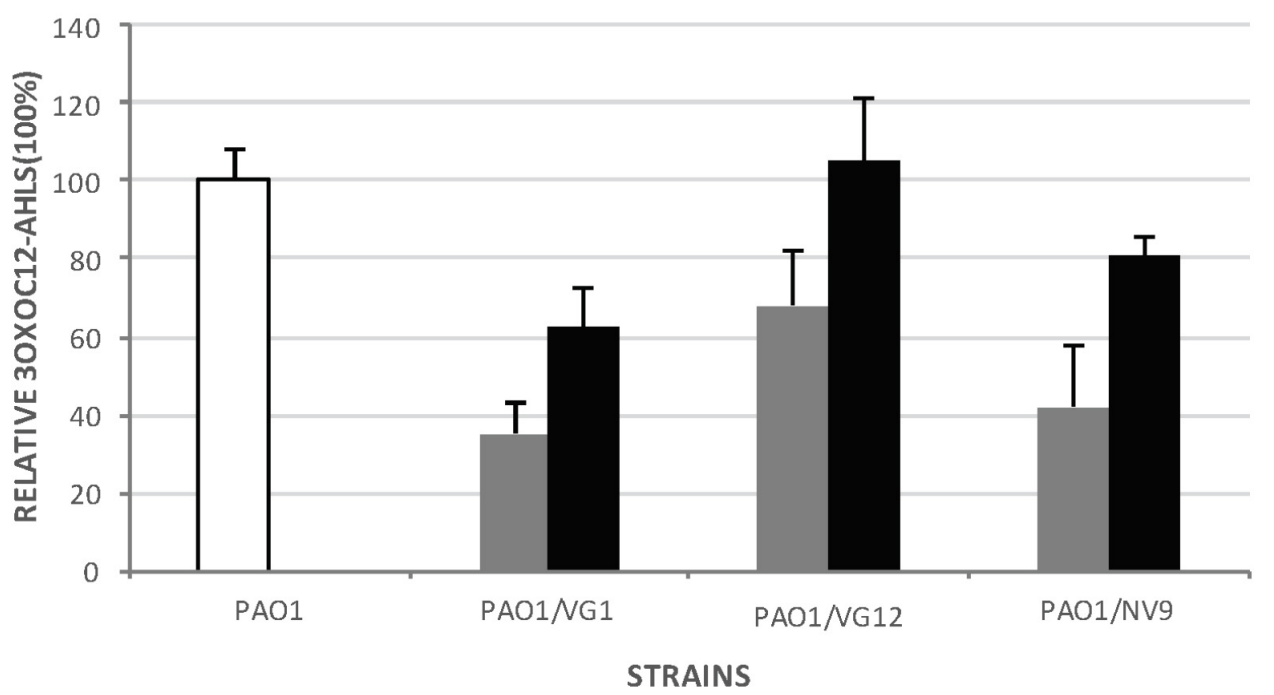

FIGURE 4 | Biofilm formation by Pseudomonas aeruginosa PAO1 incubated with live and dead QQ strains. (A) This experiment was performed in microtiter plates with membrane inserts for wells, as described in Section "Materials and Methods." The $y$-axis indicates the $\mathrm{OD}_{590}$ of the crystal violet bound to the wells. White bars represent biofilm formation by PAO1 without any live or dead QQ bacteria. Gray bars represent biofilm formation by PAO1 incubated with live QQ cells, while black bars represent biofilm formation by PAO1 incubated with dead QQ bacteria. LB broth was used as the negative control. Error bars represent the standard deviation for the three replicates. Student's $t$-test was applied to determine significance; $p$-values: VG1 (0.29), VG12 (0.04), and NV9 (0.09). (B) Relative amount of 3OXOC12-AHLs in the supernatant of PAO1 incubated with live or dead QQ bacteria. The amount of AHLs in the supernatant of PAO1 incubated with live QQ bacteria is shown as gray bars, while that detected in the presence of dead QQ bacteria is shown as black bars. The amount of AHLs produced by PAO1 (without live/dead QQ bacteria) is shown by white bars (100\%). Error bars represent the standard deviation. Student's $t$-test showed no significant difference in the amount of 3OXOC12-AHLs in the PAO1 supernatant incubated with live/dead VG1 ( $p$-value $=0.16)$, VG12 ( $p$-value $=0.219)$, and NV9 $(p$-value $=0.22$ ).

because of its low similarity with the type strain Labrenzia alba.

Annotated genomes were searched for the homologs of AHL lactonases and acylases, which are members of the metallo-beta-lactamase (MBL) and N-terminal nucleophile hydrolases (Ntn-hydrolases) superfamilies, respectively (Utari et al., 2017).

VG1 genomic annotations showed that the two ORFs (VG1_000001122 and VG1_000002328) are KEGG orthologs of AHL-lactonases (K13075). UniProt annotations 
TABLE 2 | Genomic IDs of the ORFs of the sequenced strains, showing homology to $\mathrm{AHL}$-lactonases or $\mathrm{AHL}$-acylases.

\begin{tabular}{lcc}
\hline Strains & \multicolumn{2}{c}{ ORFs (ID) } \\
\cline { 2 - 3 } & Lactonases & Acylases \\
\hline VG1 & VG1_000001122 & VG1_000002924 \\
& VG1_000002328 & \\
VG12 & VG12_000006578 & \\
& VG12_000000021 & \\
& VG12_000000913 & \\
& VG12_000003727 & \\
& VG12_000004165
\end{tabular}

NV9

NV9_000000564

Open reading frames predicted by both KEGG and UniProt are listed; the amino acid sequences of these ORFs can be accessed using the annotation links given in Section "Results."

further confirmed that these proteins are beta-lactamases. Similarly, both KEGG (K07116) and UniProt annotations suggest that ORF VG1_000002924 is an AHL-acylase (Table 2).

For VG12, both KEGG Orthology and UniProt predicted that VG12_000000021, VG12_000006578, VG12_000000913, and VG12_000004165 belong to the lactonase group and/or are MBL members. The protein product (VG12_000003727) was predicted as AHL-lactonase by KEGG, but UniProt showed it to be Ribonuclease Z. BLAST analysis of this ORF showed that it is $90 \%$ identical to the MBL superfamily of proteins (Table 2). No homolog of AHL-acylases was identified for VG12, neither by KEGG nor UniProt.

For NV9, both KEGG and UniProt annotations indicated that NV9_000000564 is an AHL-acylase (Table 2).

Apart from these ORFs, the genomes of VG1, VG12, and NV9 carry other proteins that are homologous to MBL and amidases. The locus IDs of these ORFs are given in Supplementary Table 2.

\section{DISCUSSION}

The emergence of antimicrobial resistance has underscored the need to develop new strategies to control bacterial infections and biofilms. Furthermore, the environmentally toxic biocides used in water treatment, agriculture, and oil and shipping industry warrant the search of sustainable and non-toxic alternatives. QS is a potential target for use as a new therapeutic approach because of its role in bacterial infection and biofilm formation. One such opportunity can be identified by exploring QQ because of its potential benefits.

In this study, cultivable bacteria were isolated from Red Sea sediments collected from two different niches, i.e., areas with and without vegetation. Unexpectedly, a higher number of bacteria was isolated from the samples collected from areas without vegetation, which can be attributed to the fact that vegetative bacteria require the compounds produced by plants for their growth (Supplementary Figure 1). This can also be attributed to the inherent bias observed in the plate count method. By screening all isolates, we identified that $~ 20 \%$ of the isolates exhibit QQ activity (Table 1). These results are similar to those of previous studies, which reported higher prevalence of QQ-positive bacteria in the marine environment, compared to the terrestrial environment (Romero et al., 2011; Saurav et al., 2016). It is important to note that we only used C. violaceum CV026-based assay for the initial screening of QQ bacteria, and thus, the number of positive isolates might be underestimated.

Quorum quenching bacteria have been detected and isolated from dense microbial communities in various systems (Tan et al., 2015; Saurav et al., 2016). Similarly, in this study, a higher percentage of QQ bacteria was detected from samples collected from areas with vegetation compared to those from areas without vegetation (Table 1). However, the vegetative bacteria identified in this study might not be permanently associated with seagrass because their close relatives have been isolated from different marine niches. It can also be that the microbial community associated with seagrass is dynamic, and that the QS and QQ activities play a role in the assembly of functional communities, as reported in case of tobacco rhizosphere and granular sludge community (d'Angelo-Picard et al., 2005; Tan et al., 2015). However, the biotechnological significance of QQ bacteria renders the association of these isolates with seagrass less important.

Not all QQ-positive isolates completely degraded the C6-AHLs involved in CV026 bioassay (Supplementary Figures 2A, 3). Moreover, some isolates did not show reproducible QQ activity, and thus, this inconsistency (Saurav et al., 2016) warrants further exploration of the regulatory mechanisms of expression of QQ activity. Isolates that displayed QQ activity even after heat killing (data not shown) indicate that either QQ activity is non-enzymatic and/or the loss of AHLs was due to adsorption onto cellular debris. However, it could also be attributed to the fact that the QQ is enzymatic and that these enzymes are heat resistant. A recent study has shown that Aii20J, an AHL-lactonase from Tenacibaculum sp. 20J, can retain its activity even after heating up to $100^{\circ} \mathrm{C}$ for $10 \mathrm{~min}$ (Mayer et al., 2015). We will investigate the possibility of heat-resistant enzymes in our future studies.

Based on our findings (Figures 1, 2A) and those of others (Romero et al., 2011; Torres et al., 2013; Tan et al., 2015), there appears to be a general feature: QQ bacteria capable of degrading small-chain AHLs can almost always degrade medium- and longchain AHLs. A recent study, wherein 12 QQ bacteria were identified, showed that these bacteria could degrade a variety of different AHLs, but none of them could degrade C4-AHLs (Torres et al., 2016). This suggests that future studies in search of QQ bacteria should primarily focus on identifying bacteria capable of degrading small-acyl-chain AHLs.

Although QQ activity has been observed in either cell lysate or cell-free supernatant (Uroz et al., 2005; Shepherd and Lindow, 2009), to the best of our knowledge, it has not been detected in both fractions. The QQ activity found in both the cell lysate and supernatant of VG1 might represent a new class of QQ enzymes (Supplementary Figure 2B). However, it is possible that 
QQ molecules were released into the supernatant during sample preparation. Our results showing that the cell lysates of VG1 retain QQ activity even after heating at $105^{\circ} \mathrm{C}$ (data not shown) appear to contradict the heat killing of whole cells that can result in the loss of QQ activity. The exact reason for this observation is unknown, but it is possible that in case of cell lysates, the QQ enzyme can reform its 3D structure when cooled after heating. Fractionation of VG1 cell lysates with the $10-\mathrm{kDa}$-filter rule out the possibility that QQ is caused by small-molecularweight metabolites that could be heat resistant. Unexpectedly, for VG12 and NV9, QQ activity was lost upon cell lysis. It is possible that the QQ enzymes of these strains are sensitive to our methods of cell disruption (sonication) or that these enzymes need certain factors/conditions for their activity, which are lost on cell lysis.

All QQ-positive isolates identified in this study belong to Proteobacteria (Supplementary Figure 4 and Table 1). These results are consistent with those of previous reports, where majority of the QQ bacteria identified were also Proteobacteria (Romero et al., 2011; Tan et al., 2015; Saurav et al., 2016; Torres et al., 2016). This is not surprising because Proteobacteria is predominant in various marine environments (Gonzalez and Moran, 1997).

Although disputed, it has been suggested that AHL-acylases are not active against small-acyl-chain AHLs such as C4-AHLs (Shepherd and Lindow, 2009; Czajkowski et al., 2011). If this is correct, then degradation of C4-AHLs and restoration of the degraded 3OXOC10-AHLs after acidification suggest that the QQ activity observed in NV9 is primarily caused by lactonase (Figures 2A,B). Genomic annotation of NV9 identified one ORFs (NV9_000000104) (Supplementary Table 2) that belongs to the MBL superfamily, which could be responsible for the observed QQ activity. In VG12, although the acidification of degraded AHLs restored only 2\% of AHLs (Figure 2B), the ability of VG12 to effectively degrade C4-AHLs suggests lactonase activity (Figure 2A). It is possible that, in case of VG12, the hydrolyzed lactone ring of 3OXOC10-AHLs was further modified and was unable to reform the lactone ring. Furthermore, the prediction of only AHL-lactonases in the genome sequence of VG12 (Table 2 and Supplementary Table 2) suggests that lactonases are responsible for QQ activity. Similarly, the genome sequence of a close relative of VG12, namely, Labrenzia alba CECT 755, carries only AHL-lactonases (CTQ52848.1, CTQ54016.1, CTQ52453.1, CTQ55013.1, and CTQ55918.1); no AHL-acylase was detected. For VG1, although both AHL-lactonases and acylases are predicted in the genome sequence (Table 2 and Supplementary Table 2), its inability to degrade C4-AHLs (Figure 2A) and inability to relactonize 3OXOC10-AHLs after acidification (Figure 2B) suggest that AHL-acylases are responsible for QQ activity in this case. Interestingly, unlike VG1, the genome annotation of Erythrobacter species such as E. longus strain DSM 6997 (GenBank: JMIW0000000.1), Erythrobacter sp. HL-111 (GenBank: LT629743.1), and E. citreus strain LAMA915 (GenBank: JYNE00000000.1) show only AHL-acylases (KEO91396.1, SDS44800.1, SDT09981.1, and KNH01491.1) while no AHL-lactonase was detected in these bacteria. However, this difference might be caused by the different annotation methods/pipelines used. It is important to note that some recently discovered QQ enzymes did not show any sequence homology to the typical AHL-lactonases and acylases (Torres et al., 2017). Hence, it remains possible that the observed QQ activity is caused by a new class of enzymes.

The time-course experiment showed that VG1 can quickly degrade AHLs, closely followed by VG12 (Figure 3). We used 3OXOC10-AHLs for this assay, and it is possible that slow degradation by NV9 reflects its specificity for AHLs with a certain kind of acyl chains.

None of the QQ isolates was able to completely inhibit biofilm formation (Figure 4A), may be because biofilm formation is a complex process involving many factors (Flemming et al., 2016).We also tested QQ isolates for their ability to degrade the 3OXOC12-AHLs produced by PAO1 (Figure 4B), because 3OXOC12-AHLs lie higher in the hierarchy of the QS signaling cascade and regulate the expression of other QS molecules (C4-AHLs), production of virulence factors, and formation of biofilms (Whitehead et al., 2001; Williams and Camara, 2009). The observed ineffective degradation of 3OXOC12-AHLs and biofilm inhibition might be caused by certain PAO1 metabolites that inhibited the QQ activity of our isolates. It is also possible that 3OXOC12-AHLs are not a preferred substrate for our QQ isolates. A significant reduction in biofilm formation by VG12 might be the result of effective degradation of C4-AHLs caused by this isolate (Figures 2A, 4A). Based on our results, VG12 appears to be best isolate among others for the inhibition of biofilm formation and kinetics and diversity of AHL degradation (Figures 1-3, 4A). It also appears to be the best candidate for future studies employing bacteria as an anti-biofouling agent.

Quorum quenching alone might not completely abolish bacterial infections and biofilms, but it can be used in combination with other antimicrobial agents to achieve desired results. Combinatorial therapies are gaining importance because no single therapy or drug can effectively control bacteria for longer time periods, given that the bacteria will eventually develop resistance (Fischbach, 2011). Furthermore, QQ enzymes can confer resistance against antibiotics (Kusada et al., 2017). Therefore, improved understanding of these enzymes will provide opportunities to overcome such resistance.

In this study, we found bacteria belonging to three different genera, namely, Erythrobacter, Labrenzia, and Bacterioplanes, that can degrade AHLs. Although extracted metabolite-based QQ activity has been described for Erythrobacter and Labrenzia (Saurav et al., 2016), the bacteria identified in this study represent a new species whose QQ activity has not been described before. We have identified potential QQ genes and our future studies will focus on cloning these genes and investigating their mechanism of action.

\section{AUTHOR CONTRIBUTIONS}

$\mathrm{ZR}$ and TL designed the experiments and wrote and revised the manuscript. ZR performed the experiments. 


\section{FUNDING}

This study was supported by base line funding (BAS/1/1061-0101) awarded to TL by the King Abdullah University of Science and Technology (KAUST).

\section{ACKNOWLEDGMENTS}

We are thankful to Prof. Ana Otero from the University of Santiago de Compostela, Spain, for sharing strain C. violaceum

\section{REFERENCES}

Alam, I., Antunes, A., Kamau, A. A., Ba Alawi, W., Kalkatawi, M., Stingl, U., et al. (2013). INDIGO - INtegrated data warehouse of microbial genomes with examples from the red sea extremophiles. PLoS One 8:e82210. doi: 10.1371/ journal.pone.0082210

Altschul, S. F., Madden, T. L., Schaffer, A. A., Zhang, J., Zhang, Z., Miller, W., et al. (1997). Gapped BLAST and PSI-BLAST: a new generation of protein database search programs. Nucleic Acids Res. 25, 3389-3402. doi: 10.1093/nar/25.17. 3389

Biebl, H., Pukall, R., Lunsdorf, H., Schulz, S., Allgaier, M., Tindall, B. J., et al. (2007). Description of Labrenzia alexandrii gen. nov., sp. nov., a novel alphaproteobacterium containing bacteriochlorophyll a, and a proposal for reclassification of Stappia aggregata as Labrenzia aggregata comb. nov., of Stappia marina as Labrenzia marina comb. nov. and of Stappia alba as Labrenzia alba comb. nov., and emended descriptions of the genera Pannonibacter, Stappia and Roseibium, and of the species Roseibium denhamense and Roseibium hamelinense. Int. J. Syst. Evol. Microbiol. 57, 1095-1107. doi: 10.1099/ijs.0.64821-0

Bzdrenga, J., Daude, D., Remy, B., Jacquet, P., Plener, L., Elias, M., et al. (2017). Biotechnological applications of quorum quenching enzymes. Chem. Biol. Interact. 267, 104-115. doi: 10.1016/j.cbi.2016.05.028

Camacho, M., Redondo-Gomez, S., Rodriguez-Llorente, I., Rohde, M., Sproer, C., Schumann, P., et al. (2016). Labrenzia salina sp. nov., isolated from the rhizosphere of the halophyte Arthrocnemum macrostachyum. Int. J. Syst. Evol. Microbiol. 66, 5173-5180. doi: 10.1099/ijsem.0.001492

Cao, Y., He, S., Zhou, Z., Zhang, M., Mao, W., Zhang, H., et al. (2012). Orally administered thermostable $\mathrm{N}$-acyl homoserine lactonase from Bacillus sp. strain AI96 attenuates Aeromonas hydrophila infection in zebrafish. Appl. Environ. Microbiol. 78, 1899-1908. doi: 10.1128/AEM.06139-11

Chowdhary, P. K., Keshavan, N., Nguyen, H. Q., Peterson, J. A., Gonzalez, J. E., and Haines, D. C. (2007). Bacillus megaterium CYP102A1 oxidation of acyl homoserine lactones and acyl homoserines. Biochemistry 46, 14429-14437. doi: 10.1021/bi701945j

Coffey, B. M., and Anderson, G. G. (2014). Biofilm formation in the 96-well microtiter plate. Methods Protoc. 1149, 631-641. doi: 10.1007/978-1-49390473-0_48

Czajkowski, R., Krzyzanowska, D., Karczewska, J., Atkinson, S., Przysowa, J., Lojkowska, E., et al. (2011). Inactivation of AHLs by Ochrobactrum sp A44 depends on the activity of a novel class of AHL acylase. Environ. Microbiol. Rep. 3, 59-68. doi: 10.1111/j.1758-2229.2010.00188.x

Dang, H. Y., and Lovell, C. R. (2000). Bacterial primary colonization and early succession on surfaces in marine waters as determined by amplified rRNA gene restriction analysis and sequence analysis of $16 \mathrm{~S}$ rRNA genes. Appl. Environ. Microbiol. 66, 467-475. doi: 10.1128/AEM.66.2.467-475.2000

d'Angelo-Picard, C., Faure, D., Penot, I., and Dessaux, Y. (2005). Diversity of $\mathrm{N}$-acyl homoserine lactone-producing and-degrading bacteria in soil and tobacco rhizosphere. Environ. Microbiol. 7, 1796-1808. doi: 10.1111/j.14622920.2005.00886.X

Dong, Y. H., Gusti, A. R., Zhang, Q., Xu, J. L., and Zhang, L. H. (2002). Identification of quorum-quenching $\mathrm{N}$-acyl homoserine lactonases from Bacillus species. Appl. Environ. Microbiol. 68, 1754-1759. doi: 10.1128/AEM. 68.4.1754-1759.2002
CV026 and providing helpful advice. We are also thankful to the staff at the Biosciences Core Lab and Computational Bioscience Research Centre, KAUST, for their help with DNA sequencing and analysis.

\section{SUPPLEMENTARY MATERIAL}

The Supplementary Material for this article can be found online at: https://www.frontiersin.org/articles/10.3389/fmicb. 2018.01354/full\#supplementary-material

Dong, Y. H., Wang, L. H., Xu, J. L., Zhang, H. B., Zhang, X. F., and Zhang, L. H. (2001). Quenching quorum-sensing-dependent bacterial infection by an N-acyl homoserine lactonase. Nature 411, 813-817. doi: 10.1038/35081101

Dong, Y. H., and Zhang, L. H. (2005). Quorum sensing and quorum-quenching enzymes. J. Microbiol. 43, 101-109.

Fischbach, M. A. (2011). Combination therapies for combating antimicrobial resistance. Curr. Opin. Microbiol. 14, 519-523. doi: 10.1016/j.mib.2011.08.003

Flemming, H. C., Wingender, J., Szewzyk, U., Steinberg, P., Rice, S. A., and Kjelleberg, S. (2016). Biofilms: an emergent form of bacterial life. Nat. Rev. Microbiol. 14, 563-575. doi: 10.1038/nrmicro.2016.94

Fuqua, W. C., Winans, S. C., and Greenberg, E. P. (1994). Quorum sensing in bacteria: the LuxR-LuxI family of cell density-responsive transcriptional regulators. J. Bacteriol. 176, 269-275. doi: 10.1128/jb.176.2.269-275.1994

Galloway, W. R., Hodgkinson, J. T., Bowden, S. D., Welch, M., and Spring, D. R. (2011). Quorum sensing in Gram-negative bacteria: small-molecule modulation of AHL and AI-2 quorum sensing pathways. Chem. Rev. 111, 28-67. doi: 10.1021/cr100109t

Gao, M. S., Teplitski, M., Robinson, J. B., and Bauer, W. D. (2003). Production of substances by Medicago truncatula that affect bacterial quorum sensing. Mol. Plant Microbe Interact. 16, 827-834. doi: 10.1094/MPMI.2003.16.9.827

Givskov, M., Denys, R., Manefield, M., Gram, L., Maximilien, R., Eberl, L., et al. (1996). Eukaryotic interference with homoserine lactone-mediated prokaryotic signaling. J. Bacteriol. 178, 6618-6622. doi: 10.1128/jb.178.22.6618-6622.1996

Gonzalez, J. M., and Moran, M. A. (1997). Numerical dominance of a group of marine bacteria in the alpha-subclass of the class Proteobacteria in coastal seawater. Appl. Environ. Microbiol. 63, 4237-4242.

Hentzer, M., and Givskov, M. (2003). Pharmacological inhibition of quorum sensing for the treatment of chronic bacterial infections. J. Clin. Invest. 112, 1300-1307. doi: 10.1172/JCI20074

Huang, J. H., Shi, Y. H., Zeng, G. M., Gu, Y. L., Chen, G. Q., Shi, L. X., et al. (2016). Acyl-homoserine lactone-based quorum sensing and quorum quenching hold promise to determine the performance of biological wastewater treatments: an overview. Chemosphere 157, 137-151. doi: 10.1016/j.chemosphere.2016.05.032

Kanehisa, M., Goto, S., Sato, Y., Kawashima, M., Furumichi, M., and Tanabe, M. (2014). Data, information, knowledge and principle: back to metabolism in KEGG. Nucleic Acids Res. 42, D199-D205. doi: 10.1093/nar/gkt1076

Kim, S. R., Lee, K. B., Kim, J. E., Won, Y. J., Yeon, K. M., Lee, C. H., et al. (2015). Macroencapsulation of quorum quenching bacteria by polymeric membrane layer and its application to MBR for biofouling control. J. Membr. Sci. 473, 109-117. doi: 10.1016/j.memsci.2014.09.009

Koren, S., Walenz, B. P., Berlin, K., Miller, J. R., Bergman, N. H., and Phillippy, A. M. (2017). Canu: scalable and accurate long-read assembly via adaptive k-mer weighting and repeat separation. Genome Res. 27, 722-736. doi: 10.1101/ gr.215087.116

Kumar, S., Stecher, G., and Tamura, K. (2016). MEGA7: molecular evolutionary genetics analysis version 7.0 for bigger datasets. Mol. Biol. Evol. 33, 1870-1874. doi: 10.1093/molbev/msw054

Kusada, H., Tamaki, H., Kamagata, Y., Hanada, S., and Kimura, N. (2017). A novel quorum-quenching $\mathrm{N}$-acylhomoserine lactone acylase from Acidovorax sp. Strain MR-S7 mediates antibiotic resistance. Appl. Environ. Microbiol. 83:e00080-17. doi: 10.1128/AEM.00080-17

Lee, S., Park, S. K., Kwon, H., Lee, S. H., Lee, K., Nahm, C. H., et al. (2016). Crossing the border between laboratory and field: bacterial quorum quenching 
for anti-biofouling strategy in an MBR. Environ. Sci. Technol. 50, 1788-1795. doi: 10.1021/acs.est.5b04795

Lin, Y. H., Xu, J. L., Hu, J. Y., Wang, L. H., Ong, S. L., Leadbetter, J. R., et al. (2003). Acyl-homoserine lactone acylase from Ralstonia strain XJ12B represents a novel and potent class of quorum-quenching enzymes. Mol. Microbiol. 47, 849-860. doi: 10.1046/j.1365-2958.2003.03351.x

Mayer, C., Romero, M., Muras, A., and Otero, A. (2015). Aii20J, a widespectrum thermostable $\mathrm{N}$-acylhomoserine lactonase from the marine bacterium Tenacibaculum sp. 20J, can quench AHL-mediated acid resistance in Escherichia coli. Appl. Microbiol. Biotechnol. 99, 9523-9539. doi: 10.1007/s00253-015-6741-8

McClean, K. H., Winson, M. K., Fish, L., Taylor, A., Chhabra, S. R., Camara, M., et al. (1997). Quorum sensing and Chromobacterium violaceum: exploitation of violacein production and inhibition for the detection of $\mathrm{N}$-acylhomoserine lactones. Microbiology 143, 3703-3711. doi: 10.1099/00221287-143-12-3703

Natrah, F. M. I., Defoirdt, T., Sorgeloos, P., and Bossier, P. (2011). Disruption of bacterial cell-to-cell communication by marine organisms and its relevance to aquaculture. Mar. Biotechnol. 13, 109-126. doi: 10.1007/s10126-010-9346-3

Oh, H. S., Tan, C. H., Low, J. H., Rzechowicz, M., Siddiqui, M. F., Winters, H., et al. (2017). Quorum quenching bacteria can be used to inhibit the biofouling of reverse osmosis membranes. Water Res. 112, 29-37. doi: 10.1016/j.watres.2017. 01.028

Oh, H. S., Yeon, K. M., Yang, C. S., Kim, S. R., Lee, C. H., Park, S. Y., et al. (2012). Control of membrane biofouling in MBR for wastewater treatment by quorum quenching bacteria encapsulated in microporous membrane. Environ. Sci. Technol. 46, 4877-4884. doi: 10.1021/es204312u

Pham, T. M., Wiese, J., Wenzel-Storjohann, A., and Imhoff, J. F. (2016). Diversity and antimicrobial potential of bacterial isolates associated with the soft coral Alcyonium digitatum from the Baltic Sea. Antonie Van Leeuwenhoek 109, 105-119. doi: 10.1007/s10482-015-0613-1

Quast, C., Pruesse, E., Yilmaz, P., Gerken, J., Schweer, T., Yarza, P., et al. (2013). The SILVA ribosomal RNA gene database project: improved data processing and web-based tools. Nucleic Acids Res. 41, D590-D596. doi: 10.1093/nar/gks1219

Romero, M., Diggle, S. P., Heeb, S., Camara, M., and Otero, A. (2008). Quorum quenching activity in Anabaena sp PCC 7120: identification of AiiC, a novel AHL-acylase. FEMS Microbiol. Lett. 280, 73-80. doi: 10.1111/j.1574-6968.2007. 01046.x

Romero, M., Martin-Cuadrado, A. B., Roca-Rivada, A., Cabello, A. M., and Otero, A. (2011). Quorum quenching in cultivable bacteria from dense marine coastal microbial communities. FEMS Microbiol. Ecol. 75, 205-217. doi: 10.1111/j.1574-6941.2010.01011.x

Romero, M., Muras, A., Mayer, C., Bujan, N., Magarinos, B., and Otero, A. (2014). In vitro quenching of fish pathogen Edwardsiella tarda AHL production using marine bacterium Tenacibaculum sp. strain 20J cell extracts. Dis. Aquat. Organ. 108, 217-225. doi: 10.3354/dao02697

Saurav, K., Bar-Shalom, R., Haber, M., Burgsdort, I., Oliviero, G., Costantino, V., et al. (2016). In search of alternative antibiotic drugs: quorum-quenching activity in sponges and their bacterial isolates. Front. Microbiol. 7:416. doi: $10.3389 /$ fmicb. 2016.00416

Shepherd, R. W., and Lindow, S. E. (2009). Two dissimilar N-Acyl-homoserine lactone acylases of Pseudomonas syringae influence colony and biofilm morphology. Appl. Environ. Microbiol. 75, 45-53. doi: 10.1128/AEM.01723-08

Tan, C. H., Koh, K. S., Xie, C., Zhang, J., Tan, X. H., Lee, G. P., et al. (2015). Community quorum sensing signalling and quenching: microbial granular biofilm assembly. Biofilms Microbiomes 1:15006. doi: 10.1038/npjbiofilms. 2015.6

Teasdale, M. E., Liu, J. Y., Wallace, J., Akhlaghi, F., and Rowley, D. C. (2009). Secondary metabolites produced by the marine bacterium Halobacillus salinus that inhibit quorum sensing-controlled phenotypes in gram-negative bacteria. Appl. Environ. Microbiol. 75, 567-572. doi: 10.1128/AEM.00632-08

The Uniprot Consortium (2017). UniProt: the universal protein knowledgebase. Nucleic Acids Res. 45, D158-D169. doi: 10.1093/nar/gkw1099

Torres, M., Romero, M., Prado, S., Dubert, J., Tahrioui, A., Otero, A., et al. (2013). $\mathrm{N}$-acylhomoserine lactone-degrading bacteria isolated from hatchery bivalve larval cultures. Microbiol. Res. 168, 547-554. doi: 10.1016/j.micres.2013.04.011
Torres, M., Rubio-Portillo, E., Anton, J., Ramos-Espla, A. A., Quesada, E., and Llamas, I. (2016). Selection of the $\mathrm{N}$-acylhomoserine lactone-degrading bacterium Alteromonas stellipolaris PQQ-42 and of its potential for biocontrol in aquaculture. Front. Microbiol. 7:646. doi: 10.3389/fmicb.2016.00646

Torres, M., Uroz, S., Salto, R., Fauchery, L., Quesada, E., and Llamas, I. (2017). HqiA, a novel quorum-quenching enzyme which expands the AHL lactonase family. Sci. Rep. 7:943. doi: 10.1038/s41598-017-01176-7

Uroz, S., Chhabra, S. R., Camara, M., Williams, P., Oger, P., and Dessaux, Y. (2005). N-acylhomoserine lactone quorum-sensing molecules are modified and degraded by Rhodococcus erythropolis W2 by both amidolytic and novel oxidoreductase activities. Microbiology 151, 3313-3322. doi: 10.1099/mic.0. 27961-0

Utari, P. D., Vogel, J., and Quax, W. J. (2017). Deciphering physiological functions of ahl quorum quenching acylases. Front. Microbiol. 8:1123. doi: 10.3389/fmicb. 2017.01123

Vinoj, G., Vaseeharan, B., Thomas, S., Spiers, A. J., and Shanthi, S. (2014). Quorum-quenching activity of the AHL-lactonase from Bacillus licheniformis DAHB1 inhibits Vibrio biofilm formation in vitro and reduces shrimp intestinal colonisation and mortality. Mar. Biotechnol. 16, 707-715. doi: 10.1007/s10126014-9585-9

Wang, G. H., Jia, Q. K., Li, T., Dai, S. K., Wu, H. L., He, H., et al. (2014). Bacterioplanes sanyensis gen. nov., sp. nov., a PHB-accumulating bacterium isolated from a pool of Spirulina platensis cultivation. Arch. Microbiol. 196, 739-744. doi: 10.1007/s00203-014-1009-8

Whitehead, N. A., Barnard, A. M., Slater, H., Simpson, N. J., and Salmond, G. P. (2001). Quorum-sensing in Gram-negative bacteria. FEMS Microbiol. Rev. 25, 365-404. doi: 10.1111/j.1574-6976.2001.tb 00583.x

Williams, P., and Camara, M. (2009). Quorum sensing and environmental adaptation in Pseudomonas aeruginosa: a tale of regulatory networks and multifunctional signal molecules. Curr. Opin. Microbiol. 12, 182-191. doi: 10.1016/j.mib.2009.01.005

Yang, F., Wang, L. H., Wang, J., Dong, Y. H., Hu, J. Y., and Zhang, L. H. (2005). Quorum quenching enzyme activity is widely conserved in the sera of mammalian species. FEBS Lett. 579, 3713-3717. doi: 10.1016/j.febslet.2005.05. 060

Yates, E. A., Philipp, B., Buckley, C., Atkinson, S., Chhabra, S. R., Sockett, R. E., et al. (2002). $N$-acylhomoserine lactones undergo lactonolysis in a $\mathrm{pH}$-, temperature-, and acyl chain length-dependent manner during growth of Yersinia pseudotuberculosis and Pseudomonas aeruginosa. Infect. Immun. 70, 5635-5646. doi: 10.1128/IAI.70.10.5635-5646. 2002

Yoon, J. H., Kim, H., Kim, I. G., Kang, K. H., and Park, Y. H. (2003). Erythrobacter flavus sp. nov., a slight halophile from the East Sea in Korea. Int. J. Syst. Evol. Microbiol. 53, 1169-1174. doi: 10.1099/ijs.0.02510-0

Zhang, L., Ruan, L., Hu, C., Wu, H., Chen, S., Yu, Z., et al. (2007). Fusion of the genes for AHL-lactonase and S-layer protein in Bacillus thuringiensis increases its ability to inhibit soft rot caused by Erwinia carotovora. Appl. Microbiol. Biotechnol. 74, 667-675. doi: 10.1007/s00253-0060696-8

Zhang, Y., Jiao, N. Z., Cottrell, M. T., and Kirchman, D. L. (2006). Contribution of major bacterial groups to bacterial biomass production along a salinity gradient in the South China Sea. Aquat. Microb. Ecol. 43, 233-241. doi: 10.3354/ ame 043233

Conflict of Interest Statement: The authors declare that the research was conducted in the absence of any commercial or financial relationships that could be construed as a potential conflict of interest.

Copyright (C) 2018 Rehman and Leiknes. This is an open-access article distributed under the terms of the Creative Commons Attribution License (CC BY). The use, distribution or reproduction in other forums is permitted, provided the original author(s) and the copyright owner(s) are credited and that the original publication in this journal is cited, in accordance with accepted academic practice. No use, distribution or reproduction is permitted which does not comply with these terms. 